\title{
Erratic fruit set in almond under warm climates
}

\author{
Kodad, O. ${ }^{1}$ \& Socias i Company, R. $^{2}$ \\ ${ }^{1}$ Department of Pomology, National School of Agriculture, BP S/40, Meknès, Morocco \\ ${ }^{2}$ Unidad de Fruticultura, CITA de Aragón, Av. Montañana 930, 50059 Zaragoza, Spain
}

\begin{abstract}
Summary: The cause for the erratic yields of the two main almond cultivars grown in Morocco has been searched in order to recommend possible solutions for a high and stable production. The lack of sufficient bloom overlap between 'Marcona' and 'Fournat de Brézenaud' in many years may be one of the reasons of this erratic behavior, but not the only one, as the same behaviour may be observed in two simultaneously blooming cultivars, 'Ferragnès' and 'Ferraduel'. The relatively high temperatures observed during the blooming period significantly reduced the stigma receptivity of these cultivars and, as a consequence, their effective pollination period, showing that stigmatic receptivity is a limiting factor for fruit set in 'Marcona' and 'Ferragnès' and their subsequent yield reduction under warm conditions. Thus, in the present context of global warming, the search for cultivars tolerant to heat stress during flowering will acquire a special interest, as well as the combination of cultivars with the same chilling and heat requirements to ensure a simultaneous bloom.
\end{abstract}

Keywords: Prunus amygdalus, bloom, effective pollination period, fruit set

\section{Introduction}

Almond [Prunus amygdalus Batsch syn. P. dulcis (Mill.) D.A. Webb] cultivars are, with few exceptions, self-incompatible (Socias $i$ Company, 1990). Therefore, in order to ensure that flowers may be efficiently pollinated to reach an economically acceptable fruit set, insect-dependent crosspollination of inter-compatible and simultaneously blooming cultivars is required (Kester \& Griggs, 1959). The pollination process involves the release, transport, and deposition of pollen from the anthers of the flowers to the stigma, but the success of this process depends on many variable factors, such as pollinating insects, climatic conditions and stigma receptivity. The lack of pollinating vectors or the occurrence of inadequate climatic conditions during bloom that could affect the pollinator activities may render pollen transfer difficult (Socias i Company et al., 1994). Consequently, a good fruit set has been reported to depend on a number of factors related to the efficiency of the pollination process, including the number of pollinated flowers, the effective pollination period (EPP), including stigma receptivity, pollen tube kinetics and ovule longevity, as well as temperature, flower quality, and chemical treatments during blooming time (reviewed by Sanzol \& Herrero, 2001). Kodad \& Socias i Company (2008) have also reported that besides all these factors, the inbreeding level of the genotype and its effective autonomous selfpollination must also be taken into the account when evaluating fruit set and yield.

The concept of EPP was introduced by Williams (1965) to assess floral receptivity in apple, and was defined as the period during which pollination was effective in producing fruit. This period is determined by the longevity of the ovules minus the time-lag between pollination and fertilization, provided that this resulting value does not exceed the length of stigma receptivity (Sanzol et al., 2003). Several studies have shown that stigmatic receptivity in almond is limiting the EPP, resulting as a consequence in a reduction of fruit set and yield (Griggs \& Iwakiri, 1964; Kodad \& Socias $i$ Company, 2009; Ortega et al., 2004; Vezvaei \& Jackson, 1994). The delay in the blooming period between the main cultivar and its pollenizer may accentuate this situation in self-incompatible cultivars in commercial orchards due to the lack of simultaneous flower opening and pollen release. Adequate distribution of honeybee hives and orchard design (Socias $i$ Company et al., 1994) are required to ensure early pollination of flowers at anthesis.

'Marcona' and 'Ferragnès' are two important cultivars in commercial almond orchards in many Mediterranean countries, including Morocco. These cultivars appear to be adapted to the climatic conditions of different growing regions and are highly appreciated by consumers and growers (Felipe, 2000). 'Marcona', a traditional Spanish cultivar, has been generally associated in Morocco with 'Fournat de Brézenaud', a traditional French cultivar. 'Ferragnès' is normally associated with 'Ferraduel', having been both cultivars obtained in the INRA French breeding program, issuing from the cross 'Cristomorto' $\times$ 'Ai' (Grasselly \& Crossa-Raynaud, 1980). However, these cultivars are prone to erratic fruit sets, giving as a consequence low to nil yields in some years. This situation was attributed to a delay in flowering between the main cultivars and their pollenizers. Nevertheless, a good blooming overlap has been observed in some years, but the resulting crop was low (Loussert et al., 1989). Thus, our objective was to assess the possible influence of EPP on fruit 
set and consequently on yield in 'Marcona' and 'Ferragnès' under warm climatic conditions.

\section{Materials and methods}

\section{Plant material and experimental area}

All cultivars included in this study were represented by three juxtaposed trees, planted in the experimental station established in January 2002 at the Institut National de la Recherche Agronomique (INRA), Meknès, located at $33^{\circ} 55^{\prime} \mathrm{N}$ and $5^{\circ} 13^{\prime} \mathrm{W}$, at $499 \mathrm{~m}$ over sea level. The orchard was managed according to commercial recommendations for the area, and the trees were formed as open vase.

\section{Flowering time and effective pollination period}

The blooming date was determined according to the International Plant Genetic Resources Institute (IPGRI) descriptors (Gülcan, 1985). The evaluation of the EPP was carried out during two consecutive seasons (2008-2009) according to Williams (1970). Several branches (3-4) around the trees were selected and assigned randomly to the treatments. At least 100 flower buds at stage D (Felipe, 1977) per treatment were emasculated and hand self-pollinated $0,2,4,6$ or $8 \mathrm{~d}$ after emasculation. All pistils were cross-pollinated with pollen of 'Desmayo Largueta', chosen because of its inter-compatibility with all the studied cultivars and to avoid the effect of pollen source on fruit set. Pollen was obtained by desiccating anthers for $48 \mathrm{~h}$ at room temperature and storing them at $4{ }^{\circ} \mathrm{C}$ in glass vials until pollination. Pollen viability was determined by observing the percentage of germinated pollen grains in vitro. Initial fruit set was recorded 5 weeks after pollination time and the final fruit set was recorded in June.

\section{Stigma receptivity}

Stigma receptivity was determined on the same three trees. Flowers were emasculated and hand cross-pollinated by 'Desmayo Largueta' pollen $0,2,4,6$, or $8 \mathrm{~d}$ after emasculation. After each pollination treatment, 30 flowers were collected $1 \mathrm{~d}$ after pollination, fixed in 1:1:18 (v/v/v) formaldehyde-acetic acid-70\% ethanol (FAA), rinsed several times in water, and autoclaved in a $5 \%$ solution $(\mathrm{w} / \mathrm{v})$ of $\mathrm{Na}_{2} \mathrm{SO}_{3}$ for $12 \mathrm{~min}$ at $1.2 \mathrm{~kg} \mathrm{~cm}^{-2}$. Samples were maintained at $2-4^{\circ} \mathrm{C}$ until examination of pollen germination on the stigmas. The number of pollen tubes in the upper part of the style were determined using a Leitz Ortholux II (Wetzlar, Germany) microscope with UV illumination via an Osram HBO 200 W/4 mercury lamp after staining with $0.1 \%(\mathrm{w} / \mathrm{v})$ aniline blue in 0.1M potassium phosphate (Linskens \& Esser, 1957). Each stigma was considered receptive when it was able to support pollen hydration, germination, and initial pollen-tube growth into the transmitting tissues of the style (Sanzol et al., 2003). The percentage of stigmas with pollen that germinated $1 \mathrm{~d}$ after pollination out of 25-30 stigmas examined was deter- mined as an index of stigma receptivity (altogether 25-30 stigmas were analyzed for each combination).

\section{Statistical analysis}

The statistical analyses were performed with the SAS program (SAS Institute, Cary, NC, USA). The analysis of variance with the PROC GLM procedure was applied to distinguish the effect of the genotype, time of pollination and the year on the traits studied. The genotype was considered the fixed effect and the year as the random effect. The mean separation was done using the LSD test.

\section{Results and discussion}

\section{Bloom evolution}

The phenological behaviour of any cultivar has to be known in order to establish the most adequate orchard management for obtaining satisfactory productions (Valentini et al., 2001), especially when two or more self-incompatible cultivars are planted together to ensure cross-pollination. During the two years of observations there were differences in the length and starting time of blooming for the studied cultivars (Figure. 1). In 2008, 'Marcona' bloomed four days earlier than its pollenizer 'Fournat de Brézenaud'; in 2009, however, these two cultivars showed a good flowering overlap (Figure 1). A delayed blooming period has been also observed between these two cultivars for some years during the last 20 years. Bloom date changes from year to year depending on the climatic characteristics, mainly temperature (Alonso et al., 2005; Socias i Company et al., 2003). Lang et al. (1987) reported that blooming date is considered dependent on the winter progression of temperatures, which affect differently the different stages of dormancy. 'Marcona' has been reported to have a low chilling requirement and a high heat requirement; on the contrary, 'Fournat de Brézenaud' has a very low chilling requirement and a very high heat requirement (Alonso et al., 2005; Tabuenca et al., 1972). Thus, the year-to-year differences in blooming date of these cultivars could be due to the differences in their heat requirements, as reported in other almond cultivars (Alonso et al., 2009). 'Ferragnès' and 'Ferraduel' coincided in their bloom time in both years. These cultivars show a similar behaviour independently of the climatic conditions of the year, probably because of their similar chilling and heat requirements (Alonso et al., 2005).

The high frequency of years characterised by a delayed blooming between 'Marcona' and 'Fournat de Brézenaud' could explain the erratic fruit set often observed in 'Marcona'. These cultivar has been extensively planted in mixed blocks with 'Fournat de Brézenaud' in all growing regions of Morocco, but their not sufficiently overlapping bloom periods may explain the low productivity of 'Marcona'. In the context of the global warming experienced and of the 
prevision of increasing temperatures in the future (Stour \& Agoumi, 2008), the phenological evolution of each cultivar could be differently affected and, as a consequence, the lack of bloom overlap between 'Marcona' and 'Fournat de Brézenaud' could be more and more frequent in the future. Thus, the research on new cultivars with identical chilling and heat requirements than those of 'Marcona' is advisable to avoid this situation in the future. The knowledge of the chilling and heat requirements of most cultivars would be very useful in order to design the orchard cultivar composition to ensure a full bloom overlapping and an efficient pollination. The application of this information would minimize the crop losses due to the lack of bloom synchronization in the present frame of global warming.

\section{Effective pollination period}

The productivity of almond trees depends on several factors associated with the cultivar, such as bud density and the factors determining the floriferous capability of a genotype, as well as the ability for the flower population to be pollinated and fertilised (Dicenta et al., 2006; Godini, 2002; Kodad \& Socias i Company 2006, 2008, 2009; Ortega et al., 2004). Other factors are related to the climatic and environmental conditions ( $\mathrm{Ko}$ dad \& Socias i Company, 2006; Socias $i$ Company et al., 2005). The optimum fruit number that an almond tree may sustain is between $25 \%$ and $40 \%$ of the total number of flowers produced (Godini, 2002), a goal that can be reached if the percentage of pollinated flowers is nearly $100 \%$ (Kester \& Griggs, 1959).

Initial and final fruit set was greater in 'Ferragnès' than in 'Marcona' in both years (Figure 2 and 3). Fruit set by open pollination was $27.2 \%$ for 'Ferragnès' and $20.8 \%$ for 'Marcona' in 2008, and $43.2 \%$ for 'Ferragnès' and $31.64 \%$ for 'Marcona' in 2009. The low fruit set for 'Marcona' in 2008 could be due to the lack of enough pollination because of the delayed blooming of its pollenizer (Figure 1). However, the higher fruit set of 'Ferragnès' than 'Marcona' in 2009 could be related to the environmental conditions during bloom of 'Marcona', including temperature (Figure 4). Both cultivars are characterized by medium to high bud density, with 0.62 and $0.98 \mathrm{bud} / \mathrm{cm}$ in 2008 and 0.96 and $1.12 \mathrm{bud} / \mathrm{cm}$ in 2009 for 'Ferragnès' and 'Marcona', respectively. Such values are considered enough to ensure an acceptable fruit set if the pollination process was adequate (Kodad \& Socias $i$ Company, 2008). Thus, bud density was not a limiting factor for fruit set in 2009.

The global analysis of variance showed significant differences among genotypes, pollination time and the interaction genotype $\times$ year and year $\times$ pollination time; however, the year and the interaction genotype $\times$ time of pollination effect were not significant (Table 1). When the analysis of variance was done for each pollination time, the results showed that the year effect was significant at each pollination time (Table 2 ). The significance of the year and the interaction genotype $x$ year showed clearly that fruit set depends on the genotype 
and the climatic conditions of the year (Socias $i$ Company et al., 2005). The effect of the pollination time was significant, confirming that flower age greatly affects fruit set. The significance of the interaction year $\times$ pollination time indicates that the magnitude of the initial fruit set for each pollination time changed from year to year. In 'Ferragnès', the initial fruit set for pollination at day-0 was higher in 2009 than 2008, whereas for the remaining pollination times fruit set was higher in 2008 than 2009. This different behaviour could be due to the higher ratio of mature pistils at anthesis in 2009 than 2008. In 'Marcona', the steeper decrease of initial fruit set with pollination time may be due to the higher temperatures registered in 2009 leading to a decrease in stigma receptivity. For both cultivars, the maximum fruit set was obtained during the first two days after emasculation, with a progressive decrease thereafter (Figure 2 and 3). The statistical analysis at each pollination time (Table 2) showed that the genotype effect was significant during the first 4 days after emasculation, but not after the days 6 and 8. These differences indicate that fruit set depends primarily on the genotype during the first four days after anthesis, but thereafter the environmental conditions from the main reason for the decrease of fruit set. Fruit sets for day-0 were lower than those for day-2 and day-4 (Figure 2 and 3). Vezvaei \& Jackson (1994) reported the highest fruit set in newly opened flowers of 'Nonpareil', which may be similar to 2 days after emasculation at stage D. In the present study, acceptable fruit sets were obtained following pollination from day-0 to day-4 after emasculation. A final fruit set after pollination at day-6 was considered commercially acceptable in 'Ferragnès' only in 2008 (Figure 3). Temperatures at bloom are considered one of the main factors affecting fruit set (Hedhly et al., 2003; Vasilakakis \& Porlingis, 1985) and a shorter EPP has been related to high temperatures recorded during bloom in pear (Toyoma, 1980) and apricot (Burgos et al., 1991). In our study, the warm temperatures during bloom (Figure 4) could explain the reduction of initial fruit set with pollination at day-4 in both years for 'Marcona'.

\section{Stigma receptivity}

EPP duration in fruit trees is related to stigma receptivity, pollen tube kinetics and ovule longevity, which are highly influenced by climatic factors such as temperature (reviewed by Sanzol \& Herrero, 2001). The evaluation of stigma receptivity, assessed by the percentage of flowers with germinated pollen, revealed that in 'Marcona' and 'Ferragnès' the stigmas at anthesis were mature and were able to support pollen grain adhesion, germination and penetration. The highest initial fruit set was obtained at day-2 after emasculation in both years of study, coinciding with the highest stigma receptivity (Figure 5). In 'Ferragnès', all the stigmas were receptive at day-0 after emasculation in both years, but in 'Marcona' the percentage of pistils with pollen grains on the stigma at day-0 was higher in 2009 than in 2008. The lack of stigma receptivity just after emasculation could be due to immature stigmas, as already suggested in almond ( $Y i$ et al., 2006) and pear
Table 1. Analysis of variance for initial and final fruit set in 2008 and 2009

\begin{tabular}{|c|c|c|c|c|}
\hline Source of variation & df & $\begin{array}{c}\text { Mean } \\
\text { square }\end{array}$ & F-Value & P-value \\
\hline \multicolumn{5}{|l|}{ Initial fruit set } \\
\hline Genotype (G) & 1 & 1133.4 & 30.77 & $<0.0001$ \\
\hline Year $(Y)$ & 1 & 0.22 & 0.01 & 0.9383 \\
\hline $\mathrm{G} \times \mathrm{Y}$ & 1 & 1973.16 & 53.57 & $<0.0001$ \\
\hline Pollination time (PT) & 4 & 32839.54 & 222.9 & $<0.0001$ \\
\hline $\mathrm{G} \times \mathrm{PT}$ & 4 & 922.72 & 1.51 & 0.2045 \\
\hline $\mathrm{Y} \times \mathrm{PT}$ & 4 & 2734.89 & 18.56 & $<0.0001$ \\
\hline $\mathrm{G} \times \mathrm{Y} \times \mathrm{PT}$ & 4 & 278.47 & 1.89 & 0.1180 \\
\hline Error & 100 & 36.83 & & \\
\hline \multicolumn{5}{|l|}{ Final fruit set } \\
\hline Genotype (G) & 1 & 510.9 & 15.84 & $<0.0001$ \\
\hline Year $(Y)$ & 1 & 842.1 & 26.11 & $<0.0001$ \\
\hline $\mathrm{G} \times \mathrm{Y}$ & 1 & 763.1 & 23.66 & $<0.0001$ \\
\hline Pollination time (PT) & 4 & 5906.54 & 183.12 & $<0.0001$ \\
\hline $\mathrm{G} \times \mathrm{PT}$ & 4 & 10.45 & 0.32 & 0.8611 \\
\hline $\mathrm{Y} \times \mathrm{PT}$ & 4 & 1132.2 & 35.03 & $<0.0001$ \\
\hline $\mathrm{G} \times \mathrm{Y} \times \mathrm{PT}$ & 4 & 20.5 & 0.64 & 0.6383 \\
\hline Error & 100 & 32.25 & & \\
\hline
\end{tabular}

Table 2. Analysis of variance for initial and final fruit set at each pollination time in 2008 and 2009

\begin{tabular}{|c|c|c|c|}
\hline \multirow{2}{*}{ Source of variation } & \multirow{2}{*}{ df } & \multicolumn{2}{|c|}{ Mean Square ${ }^{z}$} \\
\hline & & Initial fruit set & Final fruit set \\
\hline \multicolumn{4}{|l|}{0 -day } \\
\hline Genotype & 1 & $295.26^{*}$ & $198.62 *$ \\
\hline Year & 1 & $632.83 * *$ & $1972.06 * * *$ \\
\hline Year $\times$ Genotype & 1 & $77.76 \mathrm{~ns}$ & $47.94 \mathrm{~ns}$ \\
\hline Error & 20 & 5038 & 52.87 \\
\hline \multicolumn{4}{|l|}{ 2-days } \\
\hline Genotype & 1 & $723.36 * *$ & $88.01 \mathrm{~ns}$ \\
\hline Year & 1 & $341.03 *$ & $1785.72 * * *$ \\
\hline Year $\times$ Genotypes & 1 & $964.94 * *$ & $82.06 \mathrm{~ns}$ \\
\hline Error & 20 & 41.7 & 38.7 \\
\hline \multicolumn{4}{|l|}{ 4-days } \\
\hline Genotype & 1 & $189.07 * *$ & $202.42 *$ \\
\hline Year & 1 & $301.89 * *$ & $527.34 * *$ \\
\hline Year $\times$ Genotypes & 1 & $592.62 * * *$ & $331.97 * *$ \\
\hline Error & 20 & 50.5 & 38.9 \\
\hline \multicolumn{4}{|l|}{ 6-days } \\
\hline Genotype & 1 & $106.01 \mathrm{~ns}$ & $61.40 \mathrm{~ns}$ \\
\hline Year & 1 & $1261.79 * * *$ & $832.25^{* * *}$ \\
\hline Year $\times$ Genotypes & 1 & $320.76 * *$ & $226.25 * *$ \\
\hline Error & 20 & 30.05 & 18.61 \\
\hline \multicolumn{4}{|l|}{ 8-days } \\
\hline Genotype & 1 & $62.46 \mathrm{~ns}$ & $42.29 \mathrm{~ns}$ \\
\hline Year & 1 & $397.55^{* * *}$ & $252.85 * * *$ \\
\hline Year $\times$ Genotypes & 1 & $295.54 * * *$ & $156.87^{* *}$ \\
\hline Error & 20 & 11.04 & 12.1 \\
\hline
\end{tabular}

${ }^{\mathrm{z}} \mathrm{ns}, *, * *, * * *$ : not significant or significant at $\mathrm{P}<0.05 .0 .001$, or 0.0001 . 
(Sanzol et al., 2003). In 'Marcona' and selection S5133 it has been reported that all stigmas were receptive at anthesis (Ortega et al., 2004), but not in 'Guara' (Kodad \& Socias $i$ Company, 2009) and 'Ramillete' and 'Marta' (Ortega et al., 2004). However, in our study not all stigmas were receptive at anthesis in 'Marcona' (Figure 5), showing that the maturity of the stigma at anthesis may not only depend on the cultivar, but also on the preanthesis climatic conditions. Stigma receptivity decreased 4 days after emasculation, with greater differences in the rate of decrease in 2009 than in 2008. The loss of receptivity in almond cultivars, as in pear (Sanzol et al., 2003) and sweet cherry (Hedhly et al., 2003), is related to desiccation of the stigma, and the percent of desiccated stigmas has been related to temperature increase (Ortega et al., 2004). Yi et al. (2006) reported that the stigma tissue of almond can become necrotic even when the flowers are still receptive. This could explain the high initial fruit set obtained 4 days after anthesis, especially in 2009, when pistils showed a high percentage of necrotic and desiccated stigmas at days 6 and 8 days after emasculation, especially in 'Ferragnès'. Temperatures during the days following anthesis were high in both years of study, ranging from $19^{\circ} \mathrm{C}$ to $24^{\circ} \mathrm{C}$ (Figure 4), and could desiccate the stigmas four days after emasculation.

A high positive correlation was found between fruit set and percentage of flowers with germinated pollen, the trait used to assess stigma receptivity, in both years and for both cultivars. The correlation was $r^{2}=0.97(P=0.0034)$ in 2008, and $r^{2}=0.98(P=0.0001)$ in 2009 for 'Marcona', and $r^{2}=0.96$ $(P=0.0064)$ in 2008 and $r^{2}=0.97(P=0.0024)$ in 2009 for 'Ferragnès'. This correlation also decreased with the delay in pollination time, with a sharper decrease in 2009 than in 2008 for both cultivars. These results indicate that the length of EPP depends on stigma receptivity, which is controlled by temperatures at bloom, as reported previously (Kodad \& Socias $i$ Company, 2009; Ortega et al., 2004). Fast stigma degradation, with a subsequent shorter EPP, was the main factor limiting fruit set under warm conditions in several fruit species (Guerrero-Prieto et al., 1985; Burgos et al., 1991; Gonzalez et al., 1995; Sanzol et al., 2003). The present results clearly indicate that stigmatic receptivity could be an important factor limiting almond flower receptivity and subsequent reduction of yield performance under warm climatic conditions in Morocco, as observed during blooming of these cultivars.

\section{Conclusion}

Our results show that stigmatic receptivity is a limiting factor for fruit set in 'Marcona' and 'Ferragnès' and their subsequent yield reduction under warm conditions. In addition, the present study points out to the importance of searching for suitable pollenizers for 'Marcona', not only inter-compatible and with similar fruit characteristics, but also with a better overlapping flowering period than 'Fournat de Brézenaud'. This requirement emphasizes the importance of searching for a pollenizer with the same chilling and heat requirements as 'Marcona'. Another Spanish cultivar, 'Jordi', showing similar chilling and heat requirements as 'Marcona', as well as a completely overlapping flowering period (Alonso et al., 2005), could be used as a pollenizer instead of 'Fournat de Brézenaud'. The selection of autogamous cultivars tolerant to heat stress during flowering is another solid alternative to be taken into account under warm climatic conditions to avoid the problems related to the synchronization of the flowering period and pollination deficiencies.

\section{Acknowledgements}

This research was partially funded by the Spanish CICYT, Grupo de Investigación de Aragón A12, the National School of Agriculture of Meknès, Morocco, and INRA of Morocco. Technical assistance of by Lahlo Mohamed is gratefully acknowledged. 


\section{References}

Alonso, J.M., Ansón, J.M., Espiau, M.T. \& Socias i Company, R. (2005): Determination of endodormancy break in almond flower buds by a correlation model using the average temperature of different day interval and its application to the estimation of chill and heat requirements and blooming date. J. Amer. Soc. Hort. Sci., 130: 308-318.

Alonso, J.M., Ansón, J.M., Espiau, M.T. \& Socias i Company, R. (2009): Stability of the almond blooming date. Acta Hort., 912: 337-342.

Burgos, L., Egea, J. \& Dicenta, F. (1991): Effective pollination period in apricot (Prunus armeniaca L.) varieties. Ann. Appl. Biol. 119: 533-539.

Dicenta, F., Ortega, E. \& Egea, J. (2006): Influence of flower density on fruit set rate and production in almond. Acta Hort. 726: 307-310.

Felipe, A.J. (1977): Almendro. Estados fenológicos. Inf. Técn. Econ. Agrar., 27: 8-9.

Felipe, A.J. (2000): El almendro: el material vegetal. Integrum, Lérida. Godini, A. (2002): Almond fruitfulness and role of self-fertility. Acta. Hort., 591: 191-203.

González, M.V., Coque, M. \& Herrero, M. (1995): Stigmatic receptivity limits the effective pollination period in kiwifruit. J. Amer. Soc. Hort. Sci., 120: 199-202.

Grasselly, C. \& Crossa-Raynaud, P. (1980): L'amandier. G.P. Maisonneve et Larouse, Paris.

Griggs, W.H. \& Iwakiri, B.T. (1964): Timing is critical for effective cross pollination of almond flowers. Calif. Agric., 18: 6-7.

Guerrero-Prieto, V.M., Vasilakakis, M.D. \& Lombard, P.B. (1985): Factors controlling fruit-set of Napoleon sweet cherry in western Oregon. HortSci., 20: 913-914.

Gülcan, R. (1985): Almond descriptors (revised). IBPGR, Rome.

Hedhly, A., Hormaza, J.I. \& Herrero, M. (2003): The effect of temperature on stigmatic receptivity in sweet cherry (Prunus avium L.). Plant Cell Envir., 26: 1673-1680.

Kester, D.E. \& Griggs, W.H. (1959): Fruit setting in the almond: the effect of cross-pollinating various percentages of flowers. Proc. Amer. Soc. Hort. Sci., 74: 214-219.

Kodad, O. \& Socias i Company, R. (2006): Influence of genotype, year and type of fruiting branches on the productive behaviour of almond. Sci. Hortic., 109: 297-302.

Kodad, O. \& Socias i Company, R. (2008): Fruit set evaluation for self-compatibility selection in almond. Sci. Hortic., 118: 260-265.

Kodad, O. \& Socias i Company, R. (2009). Effect of pollination time on fruit set in an autogamous almond cultivar. J. Hort. Sci. Biotechnol., 84: 350-354.

Lang, G.A., Early, J.D., Martin, G.C. \& Darrell, R.L. (1987): Endo-, para- and endodormancy: physiological terminology and classification for dormancy research. HortSci., 22: 371-377.
Linskens, M.F. \& Esser, K. (1957): Über eine spezifische Anfarbung der Pollensläuche und die Zahl der Kallopsepfropfen nach Selbustung und Fremdung. Naturwissenchaften, 44: 16.

Loussert, R., Moussaoui, H. \& Walali, L.D.(1989): L'amandier et sa culture au Maroc. Institut Agronomique et Vétérinaire Hassan II, Rabat, Maroc.

Ortega, E., Egea, J. \& Dicenta, F.(2004): Effective pollination period in almond cultivars, HortSci., 39: 19-22.

Sanzol, J. \& Herrero, M. (2001): The effective pollination period in fruit trees. Sci. Hortic., 90: 1-17.

Sanzol, J., Rallo, P. \& Herrero, M. (2003): Stigmatic receptivity limits the effective pollination period in 'Agua de Aranjuez' pear. J. Amer. Soc. Hort. Sci., 128: 458-462.

Socias i Company, R. (1990): Breeding self-compatible almonds. Plant Breed. Rev., 8: 313-338.

Socias i Company, R., Espada, J.L. \& Felipe, A.J. (1994): The effect of orchard design on almond fruit set. HortTechnology, 4: 377-379.

Socias i Company, R., Felipe, A.J. \& Gómez Aparisi, J. (2003): Almond bloom in a changing climate. J. Amer. Pomol. Soc., 57: 89-92.

Socias i Company, R., Gómez Aparisi, J. \& Alonso, J.M. (2005): Year and enclosure effects on fruit set in an autogamous almond. Sci. Hortic., 104: 369-377.

Stour, L. \& Agoumi, A. (2008): Climatic drought in Morocco during the last decades. Hydroécol Appl., 16: 215-232.

Tabuenca, M.C., Mut, M. \& Herrero, J. (1972): Influencia de la temperatura en la época de floración de variedades de almendro. An. Estac. Exper. Aula Dei., 11: 378-395.

Toyoma, T.K. (1980): The pollen receptivity period and its relation to fruit setting in some stone fruits. Fruit Var. J., 34: 2-4.

Valentini, N., Me, G., Ferrero, R. \& Spanna, F. (2001): Use of bioclimatic indexes to characterize phonological phases of apple varieties in northern Italy. Int. J. Biometeorol., 45: 191-195.

Vasilakakis, M.D. \& Porlingis, I.C. (1985): Effect of temperature on pollen germination, pollen tube growth, effective pollination period, and fruit set of pear. HortSci., 20: 733-735.

Vezvaei, A. \& Jackson, J.F. (1994): Effect of pollen parent and stages of flower development on almond nut production. Aust. J. Exp. Agric., 35: 109-113.

Williams, R.R. (1965): The effect of summer nitrogen application on the quality of apple blossom. J. Hort. Sci., 40: 31-41.

Williams, R.R. (1970): The effect of supplementary pollination on yield. [In: R.R. Williams and R.R. Wilson (Eds.), Towards Regulated Cropping.] Grower Books, London, UK, pp. 7-10.

Yi, W., Law, S.E., McCoy, D. \& Wetzstein H.Y. (2006): Stigma development and receptivity in almond (Prunus dulcis). Ann. Bot., 97: 57-63. 